\title{
PROFISSIONALIDADE DOCENTE: SENTIDOS E SIGNIFICADOS DE UM GRUPO DE PROFESSORAS ALFABETIZADORAS
}

\section{Teacher professionality: senses and meanings of a group of literacy teachers}

\section{Profesionalidad del professor: sentidos y significados de un grupo de professores de alfabetización}

\author{
Rosilene Paula da Silva*
}

Filomena Maria de Arruda Monteiro*

\section{Resumo}

Este artigo traz resultado de pesquisa que aborda uma discussão referente a profissionalidade docente de um grupo de professoras alfabetizadoras que atuam na Rede Municipal de Várzea Grande /MT, com objetivo de compreender, a partir das narrativas, como as professoras alfabetizadoras (re)significam suas experiências no processo de constituição da profissionalidade docente. Para Roldão (2005 e 2008), a profissionalidade é resultado de vários atributos, que são constituídos no contexto social, possibilitando distinguir as profissões e sua relevância, sendo um processo progressivo de construção profissional que segue ao longo da carreira docente. Trata-se de uma pesquisa qualitativa que aborda os pressupostos teóricos da pesquisa narrativade Clandinine Connelly. O contexto é uma escola da rede municipal, com a colaboração de quatro professoras alfabetizadoras. As narrativas revelam: a complexidade do trabalho das alfabetizadoras; como as relações com o contexto escolar influenciam na profissionalidade ao longo da sua profissão e como o tempo de experiência em sala de aula possibilita ressignificar as práticas pedagógicas, com análise própria referente aos programas educacionais implantados, no contexto escolar, construindo uma ação flexível ao planejamento e ampliando a sua autonomia.

PALAVRAS-CHAVE: Profissionalidade Docente. Pesquisa Narrativa. Experiências de professoras alfabetizadoras.

\begin{abstract}
This article brings a research result that addresses a discussion referring to the teaching professionality of a group of literacy teacher who work in Municipal Network of Várzea Grande/MT, in order to understand, from the narratives, how the literacy teachers (re)signify their experiences in the process of constitution of the teaching professionalism. For Roldão

\footnotetext{
* Mestre em Educação pela Universidade Federal de Mato Grosso. Professora efetiva na Rede Municipal de Ensino em Várzea Grande/MT. Avenida Dr. Hélio Ribeiro, Condomínio UPPER, n691, T 01, apt. 601. Cuiabá/MT. CEP:78.048-250. Tel.: (65) 996224047. E-mail: rosyl2009@ hotmail.com

* Doutora em Educação pela Universidade de São Carlos. Pós doutora pela UFSCar, Líder do Grupo de Estudos e Pesquisa em Política e Formação Docentes. Professora Associada da Universidade Federal de Mato Grosso-UFMT. Rua Fernando Corrêa da Costa, no 2.367, Boa Esperança, Cuiabá/MT. CEP:78.060900. Tel.: (65) 3615-8445. E-mail: filomena@ufmt.br
} 
(2005; 2008), the professionalism is the result of several attributes, which are constituted in the social context, it possible to distinguish professions and their relevance, being a progressive process of professional construction that construction that continues throughout the teaching career. It is a qualitative research that addresses the theoretical assumptions of Clandinin and Connelly's narrative research. The context is a municipal School, with the collaboration of four literacy teachers. The narratives reveal the complexity of the literacy teacher; how the relations with the school context influence professionalism throughout their profession and how the time of experience in the classroom, makes it possible to reframe the pedagogical practices, with their own analysis regarding the educational programs implemented, in the school context, building a flexible planning action and expanding its autonomy.

KEYWORDS: Teacher Professionalism. Narrative Research. Literacy Teachers Experiences.

\section{Resumen}

Este artículo trae el resultado de una investigación que aborda una discusión sobre la profesionalidad de la enseñanza de un grupo de maestros de alfabetización que trabajan en el Municipio de Várzea Grande/MT, con objetivo comprender, a partir de las narrativas, cómo los maestros de alfabetización (re)significan sus experiencias en el proceso de constitución de la profesionalidad docente.Para Roldão (2005 y 2008), la profesionalidad es el resultado de varios atributos, que se constituyen en el contexto social, lo permite distinguir las profesiones y su relevancia, siendo un proceso progresivo de construcción professional que continua a lo largo de la Carrera docente. Es una investigación cualitativa que aborda los supuestos teóricos de la investigación narrative de Clandinin y Connelly. El contexto es una escuela municipal con la colaboración de cuatro profesores de alfabetización. Las narraciones revelan: la complejidad del trabajo de los profesores de alfabetización; cómo las relaciones con el contexto escolar influyen en el profesionalismo en toda su profesión y cómo el tiempo de experiencia en el aula permite replantear las práticas pedagógicas, con su propio análisis sobre los programas educativos implementados en el contexto escolar, construyendo una acción de planificación flexible y expandiendo su autonomía.

PALABRAS CLAVE: Profesionalidad docent. Investigación narrative. Experiencias de profesores de alfabetización.

\section{INTRODUÇÃO}

Este artigo apresenta excertos de narrativas de algumas professoras alfabetizadoras do município de Várzea Grande/MT, compondo essas os resultados de dissertação da primeira autora que está vinculada ao Programa de Pós-Graduação em Educação da Universidade Federal de Mato Grosso e o Grupo de Estudos e Pesquisas em Política e Formação Docente - GEPForDoc, intitulada "Profissionalidade Docente: Narrativa de um Grupo de Professoras Alfabetizadoras da Rede Municipal de Várzea Grande /MT”.

Desenvolvemos a pesquisa com textos partindo das narrativas das professoras em que identificamos os percursos, os fundamentos teóricos presentes, os conhecimentos e as aprendizagens construídos/reconstruídos na trajetória profissional.

A constituição da profissionalidade docente é compreendida no processo de desenvolvimento profissional, ocorrendo em diferentes momentos desse processo no contexto escolar e nas formações iniciais e continuadas. A escolha do tema surgiu das 
observações e reflexões nas experiências vividas como docente há vinte anos, atuando como professora alfabetizadora, coordenadora pedagógica e técnica da Secretaria Municipal de Educação de Várzea Grande. Assim, durante o período de formação continuada com professores desse Município, ouvimos seus diferentes discursos, destacando as diversas responsabilidades educacionais voltadas para alfabetizadores, as exigências externas que influenciavam diretamente no trabalho, na relação ensino/aprendizagem e muitos outros desafios vivenciados no contexto escolar.

Nesse sentido, indagamos: Como esse grupo de professoras alfabetizadoras se expressa, os sentidos e significados que construiu e vem construindo na constituição da sua profissionalidade docente? Como (re)significam suas práticas no processo de constituição da profissionalidade docente?

Estas indagações envolvem diversos conceitos, principalmente o da identidade profissional, que compõem o desenvolvimento da profissionalidade docente. As narrativas permitem que cada professor relembre o percurso do seu trabalho, as escolhas pedagógicas, os sentidos das formações já realizadas e a adequação para a prática na prática diária, refletindo sobre sua constituição da profissionalidade docente como alfabetizadora, em meio às diversas mudanças no sistema educacional, às interferências de políticas públicas, além das condições de trabalho, das diferentes funções desempenhadas na profissão e da contribuição de suas histórias familiar e pessoal na construção do seu "ser professor".

As referências teóricas que contemplam o trabalho de pesquisa fundamentam-se nas discussões sobre o conceito de desenvolvimento profissional e da profissionalidade docente, situando a história da alfabetização no Brasil, assim como a inserção na profissão docente, os conhecimentos e aprendizagens docentes. A pesquisa fundamentou-se nos termos metodológicos da Pesquisa Narrativa enquanto método de investigação como compreendem Clandinin e Connelly (2011).

Narrar e refletir sobre suas trajetórias formativas, suas experiências pessoais e profissionais ainda não é um costume e não se faz presente no dia a dia dos docentes. Contudo, para Schön (2000 apud HOFFMANN, 2012, p. 112-113), "é por meio do agir reflexivo que cada professor torna-se autor/reconstrutor das práticas educativas e avaliativas". Assim, apreende-se que, durante a reflexão, podem surgir indicadores significativos sobre a construção da identidade na trajetória da profissionalidade docente. Segundo Nóvoa (1995, p. 34):

\footnotetext{
a identidade não é um dado adquirido, não é uma propriedade, não é um produto. A identidade é um lugar de lutas e de conflitos, é um espaço de construção de maneiras de ser e de estar na profissão. Por isso, é mais adequado falar em processo identitário, realçando a mescla dinâmica que caracteriza a maneira como cada um se sente e se diz professor.
}

Pontuamos a importância de realizar reflexões sobre o processo de construção da profissionalidade docente e os significados de suas práticas, a partir da construção das narrativas. Assim, ao pensar nas experiências de maneira contextualizada podemos contribuir para o processo de (re)construção e compreensão da profissionalidade docente. 
A escrita de uma narrativa é uma atividade em que o narrador, nesse caso as professoras alfabetizadoras, buscam traçar a experiência de si mesma. Este exercício possibilita às professoras defrontar-se com lembranças pessoais e profissionais que revelam momentos de conflitos, que se manifestam através da escrita e do diálogo, deixando transparecer diferentes sentimentos. Desse modo, como afirmam Clandinin e Connelly (2011, p. 108), "podemos pensar que, na construção de narrativas de experiências vividas, há um processo reflexivo entre o viver, contar, reviver e recontar de uma história de vida" que possibilita analisar sua própria trajetória e reconstruir um novo olhar sobre si.

Sendo assim, o momento da reflexão sobre a ação é primordial para a professora alfabetizadora compreender a complexidade da ação formativa (MONTEIRO, 2007) diante das suas atribuições diárias no ambiente escolar, as muitas obrigações, dentre elas a de alfabetizar até uma determinada idade e concluir uma lista de conteúdos prédefinidos, distribuídos para serem abordados nessa ou naquela fase. E, ao construir a narrativa de suas experiências, possibilitará um momento de reflexão sobre como se deu a constituição da profissionalidade docente e de sua trajetória de professora alfabetizadora.

A escola contexto de pesquisa localizada na zona urbana, oferta a primeira etapa da Educação Básica com turma da Educação Infantil de quatro e cinco anos de idade. E a segunda etapa do Ensino Fundamental anos iniciais, realiza um regime misto de organização curricular, tendo o Ciclo Básico de Alfabetização Cidadão - CBAC, com o $1^{\circ}$ ciclo, que corresponde ao $1^{\circ}, 2^{\circ}$ e $3^{\circ}$ anos, e no $4^{\circ}$ ano sendo turma em regime seriado.

Esse contexto escolar é apresentado juntamente com as narrativas das quatro professoras alfabetizadoras participantes, sendo todas efetivas e que lecionam nas salas do primeiro ciclo de alfabetização, que corresponde ao $1^{\circ}, 2^{\circ}$ e $3^{\circ}$ anos da Educação Básica. Assim, na pesquisa realizada construiu-se caminhos repletos de experiências vividas e narradas pelos integrantes.

A seguir, apresentamos os caminhos percorrido na realização da pesquisa, que são trilhados entre as experiências vividas, narradas e compartilhadas pelos envolvidos. Partindo do princípio de que "no pensamento narrativo, a pessoa em contexto é o que interessa" (CLANDININ; CONNELLY, 2011, p. 66).

\section{Os caminhos da pesquisa: rumo à composição dos textos de campo}

O percurso metodológico selecionado é de grande importância para o alcance dos objetivos traçados para a pesquisa, afinal é o que possibilita atender aos objetivos propostos no estudo.

A investigação qualitativa em educação (BOGDAN; BIKLEN, 1994) agrupa diversas estratégias e muitas formas, sendo conduzida em múltiplos contextos. Visto que o objetivo não é de responder questões prévias ou testar alguma hipótese, busca compreender os sentidos e significados na visão das participantes da pesquisa. Assim, a pesquisa qualitativa permite compreender os fenômenos de maneira detalhada, traçando características minuciosas de um único participante, partindo do seu contexto social, das ações e dos comportamentos apresentados em diferentes situações nesses lugares.

O tipo de pesquisa realizada teve a perspectiva da pesquisa narrativa, sendo está um dos tipos que utilizam a abordagem qualitativa, com foco nas narrativas das 
professoras alfabetizadoras sobre suas trajetórias, de formação e experiências na constituição da profissionalidade docente. Isso implica compreender a professora em sua ação num determinado lugar, o sentido e significado atribuídos a suas práticas pedagógicas e constituindo uma cultura da própria profissão (TARDIF; LESSARD, 2008).

Ao realizar a pesquisa percebeu-se a necessidade de se inserir no contexto escolar, compreender os momentos que envolvem as suas atividades, como constroem suas reflexões e seus conhecimentos ampliando sua formação. Para o desenvolvimento da pesquisa partindo das participantes, que atuam e são autoras do processo formativo de seu desenvolvimento, faz-se necessário um pesquisador que explore a questão, para refletir em termos de relação de responsabilidade com o outro.

Nesse processo, Clandinin e Connelly (2011, p. 228) consideram que "o senso de responsabilidade relacional é o melhor caminho para refletir ao invés de pensar sobre esse problema como uma questão de propriedade." Ter um olhar atento e a sensibilidade em uma reflexão sobre si mesmo e os sentidos atribuídos às histórias narradas pelos participantes, procurando e compondo o "texto de pesquisa é condicional. É condicional aos nossos interesses e circunstâncias envolvidas" (CLANDININ; CONNELY, 2011, p. 230).

A composição dos textos de campo constituiu-se de quatro momentos, sendo os seguintes: o primeiro momento consistiu em levantamento de publicações, estudos bibliográficos sobre a temática da alfabetização e do desenvolvimento da profissionalidade, análise de alguns documentos que regem a organização da unidade escolar, como Projeto Político Pedagógico, Proposta Curricular, Plano de Aula das professoras, além de observações da rotina, como a entrada e saída dos alunos, a organização no momento do intervalo, a reunião dos professores e algumas datas comemorativas.

No levantamento de pesquisas relacionadas ao estudo sobre a profissionalidade docente identificamos que o tema era muito utilizado nas Teses e Dissertações, pois no mapeamento realizado no banco de dados da CAPES, buscando dados mais recentes, observamos grande número de trabalhos em um recorte da linha temporal no período de 2013 - 2018. Realizando uma nova busca nesse mesmo período, porém com os descritores voltados para narrativa de professores alfabetizadores e a profissionalidade docente, o número de pesquisas reduziu-se significativamente. A busca configurou-se com as áreas de concentração: educação e formação, educação escolar e profissão docente, ensino e aprendizagem e formação de professores, totalizando 399 pesquisas já realizadas. Analisando essa seleção, constatamos que 142 trabalhos tinham o foco na formação de professores, na sequência educação escolar e profissão docente com 130 estudos. Já o ensino e aprendizagem com 69 pesquisas e, por fim, educação e formação com 58 pesquisas.

Com o levantamento das 399 pesquisas no recorte temporal feito, percebemos que o ano de 2017 foi o período com maior número de pesquisas, com o total de 74, sendo que em 2013 houve uma quantidade bem próxima com 71. Em 2015 constam 69 trabalhos, em 2016, 65, já no ano de 2018 o número é de 64 e menor em 2014, com o total de 56 pesquisas. 
Com análise dos trabalhos selecionados a partir dos títulos, palavras-chaves e leitura dos resumos, foi possível reunir os trabalhos considerando proximidade com a temática. Após eliminar os estudos que não contemplavam o delineamento dos objetivos definidos, revistamos cinco dissertações e apenas uma tese. Destacamos que os estudos catalogados abordam principalmente o assunto profissionalidade e/ou professores da educação básica e não encontramos trabalhos realizados contendo os três descritores narrativas/ profissionalidade docente/ professor alfabetizador presentes em uma mesma pesquisa.

No segundo momento, realizamos conversas com quatro professoras alfabetizadoras da escola municipal lócus da pesquisa. Na conversa individual, buscamos estabelecer vínculo de confiança, proximidade, propiciando momentos de negociar relações, propósitos e ética entre participantes e pesquisadora. Clandinin e Connelly (2011, p. 153) destacam que "na verdade, há uma sondagem em uma conversa, uma sondagem profunda, mas é feita em uma situação de confiança mútua, de escuta, e de solidariedade com a experiência descrita pelo outro", momento em que a proposta da pesquisa foi apresentada, destacando a importância da participação das professoras para obter êxito na investigação.

Nessa primeira conversa com as professoras, sentimos que as narrativas eram muitas, pois algumas já estavam narrando como o contexto da alfabetização possuía suas especificidades. Com as conversas, conseguimos facilitar as escutas das narrativas orais e compreender os sentidos das experiências, presentes ao contarem suas trajetórias na constituição da profissionalidade docente, já que "a memória não é apenas mero 'registro', talvez seja mais adequado pensar nela como uma influência do mundo sobre os indivíduos", conforme afirmou Foster (2011, p. 19).

O terceiro momento foi a escrita de narrativas, com utilização de um caderno de anotação que traz na sua abertura um resumo da trajetória da constituição profissionalidade docente da primeira pesquisadora, sendo está uma forma das professoras participantes da pesquisa conhecerem um pouco a pesquisadora. Nesse resumo, o texto finaliza convidando as professoras alfabetizadoras a realizarem suas escritas narrativas sobre a constituição da profissionalidade docente.

A escrita narrativa é uma maneira de refletir sobre os diferentes contextos de sua vida. $\mathrm{O}$ texto foi se constituindo em uma escrita muito particular que apresentava a vida familiar, as atitudes dos pais em relação à educação, a comunidade em que viviam, as famílias, as escolas que frequentaram, fatos de como o sistema educacional era na época na sua formação inicial, como ingressou na docência e os sentimentos presentes naquele contexto.

As narrativas escritas ou contadas são experiências da pessoa; assim, para Dewey (1976, p. 25-26), "toda experiência modifica quem a faz e por ela passa e a modificação afeta quer o queiramos ou não, a qualidade das experiências subsequentes, pois é outra, de algum modo, a pessoa que vai passar essas novas experiências." Assim, ao realizar reflexão para produzir sua narrativa, surge a possibilidade de novas experiências, sendo possível identificar, nesses relatos, experiências já vivenciadas pelas professoras alfabetizadoras na constituição e ressignificações da profissionalidade docente, apresentando questões referentes à área profissional, a sua trajetória de vida, às teorias implícitas na sua prática, à maneira como seleciona os aspectos relevantes e ao mesmo tempo organiza de maneira coerente. É no processo de reflexão que "o princípio de continuidade de experiência significa que toda e qualquer experiência toma algo das 
experiências passadas e modifica de algum modo as experiências subsequentes" (DEWEY, 1976, p. 26).

Nos estudos de Clandinin e Connelly (2011), partindo da concepção de experiência, a investigação narrativa se caracteriza pelos termos: pessoal e social (interação); passado, presente e futuro (continuidade); associado à noção de lugar (situação). Com o agrupamento desses termos, cria-se um espaço chamado pelos autores de espaço tridimensional. Argumentam que "[...] os estudos têm dimensões e abordam assuntos temporais; focam no pessoal e no social em um balaço adequado para a investigação; e ocorrem em lugares específicos ou sequências de lugares" (CLANDININ; CONNELLY, 2011, p. 85), caracterizando-se em três elementos que compõem esse espaço da pesquisa narrativa: temporalidade, socialidade e lugar.

Nas escritas da narrativa, é possível perceber que cada professora realizou de maneira bem particular a sua, selecionando de maneira visível fatos que realmente marcaram sua trajetória profissional e de vida; desse modo, foi possível conhecer a trajetória percorrida, as lutas e vitória presentes nesse percurso.

Figura 1 - Cadernos das escritas das narrativas das professoras alfabetizadoras

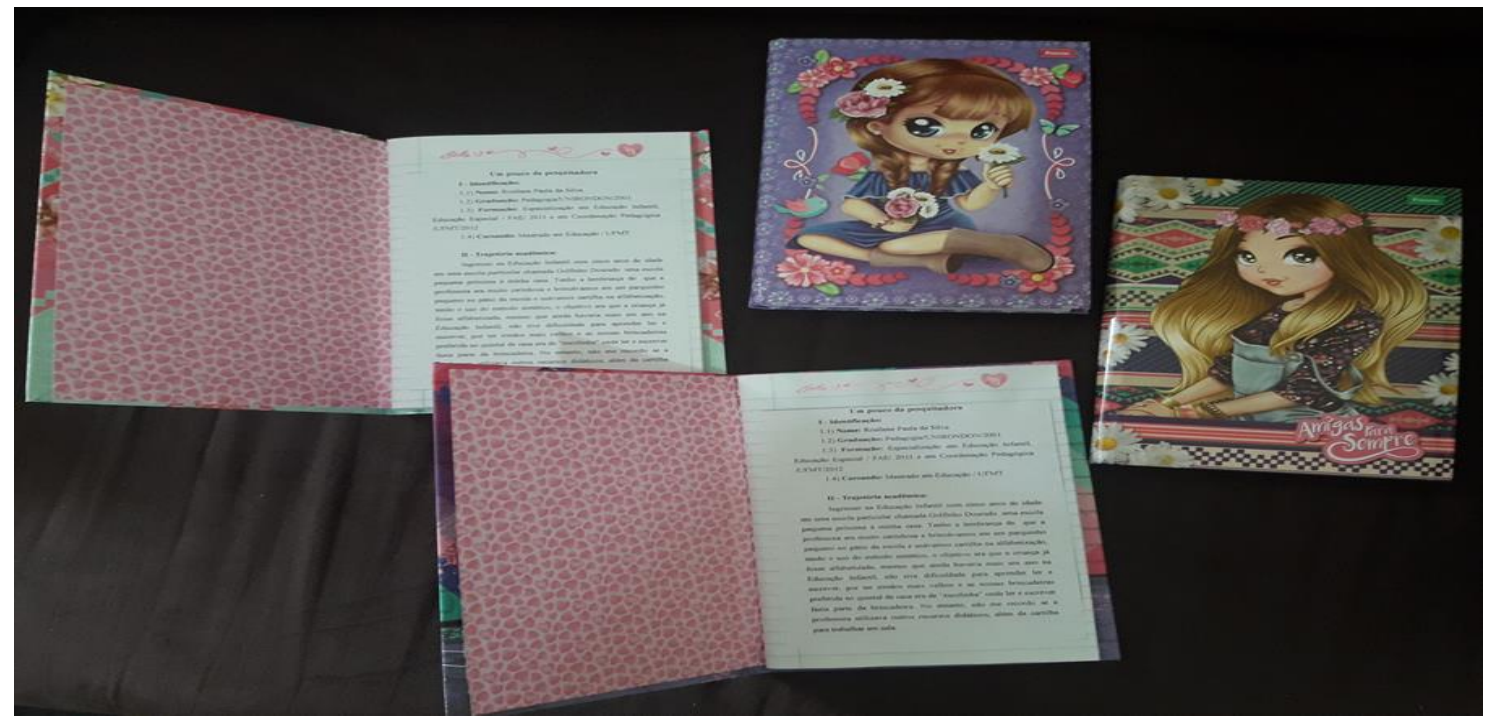

Fonte: Arquivo da pesquisadora. (2019)

O quarto momento foi a entrevista narrativa, referenciada em Clandinin e Connelly (2011) como resultante das conversas sobre as experiências profissional e acadêmica, do reconhecimento da sua caminhada, sendo essas gravadas em áudio, buscando que "os participantes contem suas próprias histórias, a sua própria maneira" (CLANDININ; CONNELLY, 2011, p. 154). Estabelecendo uma relação entre a pesquisadora e as participantes, as entrevistas ocorreram durante todo o percurso da pesquisa, com indagações sobre assuntos abordados pela professora no caderno de anotação, aprofundando temáticas que fornecem as ideias principais com as quais as participantes estruturam os relatos de experiências sobre o desenvolvimento da profissionalidade.

As entrevistas foram realizadas em encontros individualizados, no respectivo espaço de trabalho, acontecendo somente uma entrevista com uma das professoras em 
uma sorveteria. Respeitando a escolha do espaço e do tempo de cada participante, cada entrevista foi gravada com a finalidade de que a fala das professoras com a pesquisadora permitisse apontar aspectos referentes às experiências, às formações realizadas ao longo dos anos como professoras alfabetizadoras e, desta maneira, auxiliando para compor as notas de campo, que são registros frequentes de toda ação e sentimento vivenciado pelo pesquisador durante a pesquisa. Afirmam Clandinin e Connelly (2011, p. 147) que "essas anotações diárias, cheias de detalhes e momentos de nossas vidas de pesquisa, são o texto sem o qual não podemos contar histórias de nossas histórias de experiências".

A transcrição minuciosa das entrevistas narrativas para composição do texto de campo sobre as experiências das professoras alfabetizadoras foi realizada de maneira reflexiva, buscando compreender os significados das experiências, reconhecer como se desencadeou a constituição da profissionalidade docente, na relação com as formações inicial e continuada, nas ações com a professora durante a sua trajetória.

Ressaltamos que, na pesquisa narrativa, no texto de campo, cria-se um espaço com relacionamento colaborativo, buscando o contexto e experiências da professora alfabetizadora e da pesquisadora, marcados pelos termos situação, continuidade $e$ interação, que embasam a pesquisa narrativa. Partindo deles, na pesquisa narrativa, "as pessoas vivem histórias e no contar dessas histórias se reafirmam. Modificam-se e criam novas histórias. As histórias vividas e contadas educam a nós mesmos e aos outros" (CLANDININ; CONNELLYN, 1994, apud CLANDININ; CONNELLYN, 2011, p. 27).

$\mathrm{Na}$ pesquisa as identidades das professoras são fictícia, tendo sido criada pelas próprias participantes junto com a pesquisadora. Optamos por dar nomes de pedras preciosas, pois essas são minerais cristalinos raros e de importante valor, tendo esses minérios à sua particularidade, seus componentes e significados. Como cada professora participante da pesquisa, com as suas narrativas, possui uma particularidade, repleta de experiências e significados, decidimos nomeá-las como Cristal, Topázio, Rubi e Jade. Todas as participantes possuem formação em nível superior, com Pós-Graduação, são efetivas na rede municipal, com tempo de experiência entre sete a trinta anos na profissão docente, lecionando em diferentes instituições de ensino e que atualmente estava na turma de alfabetização.

Das quatro professoras alfabetizadoras participantes, a entrevista narrativa gerou um amplo material de pesquisa e considero que cada relato contribuiu de maneira consistente para a realização do trabalho, já que cada fala, emoção presente, detalhes nas lembranças revelaram o processo de constituição da profissionalidade, porém neste artigo iremos apresentar apenas algumas narrativas das participantes.

\section{As narrativas em diálogo}

As experiências narradas pelas participantes referentes ao percurso no desenvolvendo da sua profissionalidade docente constituiu a forma de estruturar o texto de pesquisa. Assim, após realizada a leitura das narrativas escritas e reflexão sobre seu conteúdo, as entrevistas narrativas, as notas de campos, tendo como base os questionamentos que orientaram a pesquisa, visando à compreensão do contexto e lugares das experiências nos quais ocorrem o desenvolvimento da profissionalidade. Deste modo, apresentamos o percurso das experiências das participantes em três eixos temáticos: I. As Experiências na Inserção da Profissão Docente; II. Atuação na Alfabetização: Conhecimentos e Aprendizagens; e III. A Identidade Profissional 
Constituída no Desenvolvimento da Profissionalidade.

No primeiro eixo temático as participantes trazer em suas narrativas as experiências na inserção na profissão docente, a professora Topázio comenta que a sua inserção ocorreu em unidades escolares particulares, destacando que durante realmente na questão do estágio da prática que pude vivenciar de perto que eu tinha algo a fazer pelas crianças, na questão da teoria, mas como é que vou trabalhar isso. A valorização do espaço em que realizou o estágio motivou muito a atuação da professora, pois realizou observação da atuação dos professores e participou de diferentes formações. Segundo a professora:

A gente faz o estágio supervisionado no Ensino Fundamental, a gente consegue ver de maneira diferente como é implicado realmente como vai ser essa prática, a partir daí começou a despertar em mim um gosto, um prazer realmente por lecionar. Aí eu tive o prazer de fazer o estágio no Sesi, foi importante uma empresa que pude aprender muito. Fiz estágio no Sesi e tive oportunidade de conhecer vários assim métodos, vários profissionais que realmente eu fui vivenciar a teoria, eu tive várias experiências ter conhecimentos muito válidos. (Professora TOPÁZIO, Entrevista Narrativa, 04/2019).

Nota-se que durante a inserção na docência da professora Topázio, ela teve oportunidade de observar outros professores e ser acolhida no espaço escolar, possibilitando ter experiências que posteriormente pôde utilizar na prática docente, passando pelo período de "sentir" e "ver", apresentado por Vaillant e Garcia (2012) no momento de estágio, possibilitando criar a sua maneira de desenvolver as capacidades e habilidades para docência. Na continuidade da entrevista, a professora diz que os desafios foram muitos no início da carreira, relatando que em "todo lugar que você trabalha, querendo ou não, sempre tem um profissional ou outro que de uma maneira te vê de forma desacreditada".

Nesta parte da narrativa, percebemos a importância de ter o seu trabalho reconhecido ou de seus pares confiarem no seu desempenho na atuação em sala de aula. Em seguida, a professora Topázio mostra a importância das parcerias nesse momento de inserção, citando que "a equipe gestora é de suma importância para desenvolver ali o meu trabalho de melhor maneira". Nesse período de inserção, o relacionamento com a equipe escolar, o entendimento da organização estrutural da escola, as regras ali estabelecidas contribuem de maneira significativa para o desenvolvimento da profissionalidade.

No segundo eixo abordado na pesquisa realizamos o diálogo com as professoras participantes referente as experiências vivenciadas na atuação em sala de aula, como as práticas contribuem para a construção dos conhecimentos e aprendizagens no desenvolvimento profissional. Ressaltamos em nossa pesquisa como a educação passou por muitas propostas educativas até os dias atuais. E, segundo Gatti (2014), passamos por uma crise na formação de professores que atuam na educação básica.

Na narrativa da professora alfabetizadora Jade se refere à ação em sala e apresenta as dificuldades de docente nos tempos de hoje. Na entrevista, narra que a rotina de sua sala começa com a acolhida na quadra, junto com todas as crianças da escola, seguindo em fila para a sala de aula, e continua da seguinte maneira:

Eu conto uma história, uma leitura deleite, pego um livro que não tem nada a ver com o contexto da aula, para a criança poder ter o gosto pela leitura 
mesmo, eu acredito que a gente não, para ter amor pela leitura que começa por aí. Tomo o alfabeto de todo mundo, chamo no particular, aquele um que fala, o outro vai na beira, finge que sabe, mas não sabe. Depois eu tomo o silabário simples, pois não consigo ainda entrar na complexa ainda com alguns, pois alguns deles, não sei o que aconteceu, estão muito devagar ainda. Eles vieram da educação infantil muito fraca, diferente dos meus alunos do ano passado, que esse mês já estavam quase todos alfabetizados, diferente deste ano, que tenho dois alfabetizados. (Professora JADE, Entrevista Narrativa, 08/2019).

Conforme a narrativa da professora Jade vê-se que na sua atuação em sala busca respeitar esse período de transição que ocorre da Educação Infantil para o primeiro ano, respeitando o tempo de aprendizagem da turma; percebo que, mesmo já tendo lecionado na turma de primeiro ano, isso não significa que os avanços são iguais e que procura compreender o que está acontecendo com os alunos em relação ao pouco avanço que está ocorrendo na aprendizagem. É interessante a leitura deleite que a professora realiza na turma; percebemos que é diferente da outra professora participante que usa a leitura para introduzir algum conteúdo, enquanto a professora Jade narra que a realiza para desenvolver o gosto pela leitura, sendo assim uma forma de torná-la prazerosa e constituir novos apreciadores da leitura.

Na continuidade da narrativa a professora Jade apresenta questões que ocorrem com muitos docentes, principalmente na inserção na carreira, como as tentativas para definir a metodologia em sala, através de observação, dicas da prática metodológica que deram certo na turma dos colegas e que assim, pode dar certo em sua turma também. A professora continua a narrativa sobre sua atuação em sala narrando que:

\begin{abstract}
[...]Eu faço grupo de quatro, para agrupamento produtivo, atividades por nível. [...] volto todo mundopara fila, volto dos grupos e faço atividade geral porque você tem que fazer atividade do primeiro ano, do segundo ano também, que eu tenho duas turmas e tem que ser no geral, porque a mãe depois vem na reunião e pergunta porque a atividade de fulano é diferente da minha, aí a mãe não entende que o filho dela não está entendendo e que ele precisa de uma aula de reforço e que aqui na escola não tem. O município de Várzea Grande não tem apoio, diferente de Cuiabá, então trabalho com muitas cópias, com quadro, indo no quadro para responder, para destravar as mãos deles em quais atividades, no quadro aí verifica se escreve um fato, tem alguns que tem, escreve espelhado, aí eu falo 'não é assim', ai eles vêm, 'ah é verdade', e corrijo e percebe a diferença. (Professora JADE, Entrevista Narrativa, 08/2019).
\end{abstract}

A professora Jade traz nessa sua narrativa a realidade do acompanhamento das famílias que não têm conhecimento referente à metodologia do trabalho diferenciado que é aplicado nas turmas do CBAC, buscando respeitar a individualidade e o tempo de aprendizagem de cada aluno e que, por isso, as comparações com os colegas não devem ocorrer.

Uma pesquisa com narrativas sobre o desenvolvimento da profissionalidade busca as experiências docentes na sua trajetória, considerando que é nesse percurso que a construção da identidade profissional ocorre, pois, no contexto da profissionalização está a profissionalidade que desencadeia e demarca durante a atuação o seu papel, função e capacidade específica da profissão docente.

Neste contexto, Pimenta (2012, p. 20) considera que "uma identidade 
profissional se constrói, pois, a partir da significação social da profissão, da revisão das tradições." Acrescenta autora que: "da reafirmação de práticas consagradas culturalmente e que permanecem significativas". Sobre o eixo temático: as identidades profissionais constituídas no desenvolvimento da profissionalidade, assim expressa a professora Cristal em sua narrativa:

Para construir a minha identidade enquanto professora é muito importante eu compreender essa concepção para poder atuar. Se eu não compreendo o que é ser professor eu vou confundir ser professora com todas outras funções e menos eu ser professora. Na minha opinião, concepção o que é ser professora é alguém que está com compromisso maior, um compromisso fechado com a sala de aula na qual a minha grande responsabilidade é possibilitar momento de aprendizagem, de troca de interação. Eu sei que outras funções podem fazer isso, mas a partir do momento que eu coloquei isso, que eu estou em um ambiente escolar para ser profissional, eu deixei minhas particularidades, eu entendi que aqui é o meu ambiente de trabalho, aqui não é um ambiente que possa estar como minha casa, embora esteja à vontade, mas não é como estar na minha casa, é diferente, né, então essa concepção de profissional pra mim ela é muito importante. Eu me defini, qual que é o meu papel, minha função na sala de aula enquanto professora, de mediar, de possibilitar aprendizado, de tocar, de promover o conhecimento, de demonstrar o conhecimento. Não é só o que está em um livro, que o conhecimento é a partir de tudo que a gente vive com os alunos e que eles podem aprender, todos eles podem aprender determinado ponto desde que eles sejam conduzidos, trabalhados. Eu penso que a identidade ela é a chave para o nosso trabalho. (Professora CRISTAL, Entrevista Narrativa, 09/2019).

A professora alfabetizadora Cristal reafirma em sua narrativa que é muito importante compreender sua identidade para poder atuar na prática, saber o que é ser professora, acreditando que assim melhor desenvolve o seu trabalho. Sendo, a identidade profissional dos docentes compreendida por Garcia; Hypolito; Vieira (2005, p. 54) como:

[...] uma construção social marcada por múltiplos fatores que interagem entre si, resultando numa série de representações que os docentes fazem de si mesmos e de suas funções, estabelecendo, consciente e inconscientemente, negociações das quais certamente fazem parte suas histórias de vida, suas condições concretas de trabalho, o imaginário recorrente acerca dessa profissão.

A experiência narrada pela professora alfabetizadora Cristal nos possibilita refletir sobre a compreensão dos autores acima citados, em relação a identidade e como são constituídas na relação social, de forma concreta nas suas funções, no conhecimento próprio em meio ao desempenho de suas atribuições e no seu papel na sociedade.

\section{CONSIDERAÇÕES FINAIS}

As considerações realizadas na pesquisa são constituídas por reflexões sobre ações repletas de experiências pessoais e profissionais, pensando no lugar, os sentimentos vivenciados no contexto em que a pesquisa foi realizada e em muitos outros lugares onde a pesquisadora e as professoras colaboradoras viveram histórias e as reviveram ao narrá-las. Assim, as experiências vivenciadas no passado, através das narrativas, fazem parecer que esse tempo se torna presente. 
As narrativas presentes na pesquisa são de professoras com diferentes tempos de experiência na docência, que atualmente são alfabetizadoras, porém, as experiências narradas ocorreram em diferentes espaços educacionais.

A reflexão das narrativas sobre a inserção na profissão docente, seja no ensino médio em Magistério ou na Graduação em Pedagogia, revela que a adaptação na função docência se constrói na prática em sala de aula, desenvolvendo as habilidades, buscando a construção de conhecimento, no relacionamento com seus pares, observando os professores mais experientes, sendo momentos de exigências pessoais, profissionais e tensões presentes nos primeiros anos, em que realizam a transição de estudantes para docente.

Assim, vale destacar como Garcia (1999), que o papel fundamental na escola devia ser da equipe gestora nesse período de iniciação, apoiando o docente e possibilitando sua melhor interação, de maneira que facilite essa adaptação, além da necessidade de construir propostas nos cursos de formação de Pedagogia e do próprio sistema de ensino, visando preparar os estudantes para essa inserção na docência, pois todos contribuem para tornar esse período menos tenso aos professores iniciantes, permitindo-lhes adquirir conhecimentos, construir relações, possibilitando a melhoria pessoal de todos os envolvidos e contribuindo com a constituição da identidade profissional e a sua profissionalidade docente.

Referente a atuação na alfabetização, os conhecimentos e aprendizagens necessárias no desempenho da prática pedagógica e como contribuem para o desenvolvimento da profissionalidade, é revelada, através das narrativas das professoras, a complexidade do trabalho de uma professora alfabetizadora na relação com alunos e pais, repleta de detalhes, com ações diferenciadas, cujo objetivo principal é ensinar essa criança interagir no contexto social da leitura e escrita.

Nas narrativas das professoras com maior tempo de experiência em sala de aula, percebemos que a maneira de atuarem em sala é muito particular, já que possuem um olhar de como poderia implantar certo tipo de metodologia, mesmo que seja imposta por programas educacionais, sendo comum o uso da flexibilidade na ação do planejamento, além de uma percepção referente ao espaço escolar e à autonomia em definir certas ações em sua sala e no grupo de trabalho. Assim, relatam que muitas ações implantadas pelo governo quase não têm "novidade", sendo muito parecidas com outros programas antigos e que nem sempre podem contribuir com sua ação em sala. Observamos que as várias mudanças na maneira de trabalhar na alfabetização ocorrem diante das dificuldades no sistema educacional em efetivar a aprendizagem nesta etapa de ensino.

Com base nas narrativas, consideramos que o conjunto de ações, conhecimentos e aprendizagens das professoras alfabetizadoras foi constituído em diversos momentos e ao longo dos tempos, através de experiências significativas, no desenvolvimento das suas atividades práticas, com as exigências do sistema educacional, nas observações de outros colegas de trabalho no exercício de suas funções, nas formações iniciais e continuadas realizadas por própria escolha ou imposição dos órgãos governamentais ao longo da trajetória profissional e nas reflexões realizadas sobre suas experiências e o seu papel no espaço social.

As professoras alfabetizadoras participantes ao narrarem sobre suas experiências na constituição da sua profissionalidade docente, revelam parte do processo de 
desenvolvimento da profissionalidade, permeado por fatores que envolvem influência familiar, relação interpessoal no trabalho, escolhas pessoais, possibilidade de ajudar a família, além disso, destacam em suas falas dois princípios das ações pedagógicas: a importância do trabalho coletivo e a preocupação com a aprendizagem dos alunos.

Nesse contexto, de constituição da profissionalidade docente nos remetemos ao que diz Monteiro (2017, p. 32), a respeito da relação de compartilhamento com seus pares, apresentando os problemas e dilemas existentes no contexto educacional em que se está atuando: é no exercício do trabalho reflexivo que realmente ocorre a profissionalidade docente. Assim, é importante destacar que o processo de desenvolvimento da profissionalidade docente deve assumir esse caráter de reflexão contínua, que renova os conhecimentos em sua interação pessoal, social e profissional, durante a atuação nos diferentes espaços (lugares), na prática como sujeito com autonomia de sua formação e escolhas, no sentido de configurar o trajeto da constituição da sua identidade.

Entendemos com a realização da pesquisa que o processo de constituição da profissionalidade docente abrange diferentes contextos, lugares e experiências ocorridas nesse processo, sendo (re)significados nas relações existentes em meio aos desafios, tensões, e conflitos, sofrendo impacto das políticas públicas educacionais, das ações formativas e que durante prática diária no exercício da docência vão ampliando, negociando, obtendo autonomia e tendo sua própria identidade e constituindo a profissionalidade docente.

\section{REFERÊNCIAS}

BOGDAN, R. C.; BIKLEN S. K. Investigação qualitativa em educação: uma introdução à teoria e aos métodos. Tradução: Maria João Alvarez; Sara Bahia dos Santos; Telmo Moutinho Baptista. Portugal: Ed. Porto, 1994.

CLANDININ, D.J.; CONNELLY, F M. Pesquisa narrativa: experiências e história na pesquisa qualitativa. Tradução: Grupo de Pesquisa Narrativa e Educação de Professores ILEEL/UFU. - Uberlândia: EDUFU, 2011.

DEWEY, J. Experiência e educação. Tradução de Anísio Teixeira. 2. ed. São Paulo: Ed. Nacional, 1976.

FOSTER, J. K. Memória. Tradução Camila Werner. Porto Alegre: L\&PM, 2011.

GARCIA, M. C. Formação de professores: para uma mudança educativa. Tradução de Isabel Narciso. Portugal: Editora Porto, 1999.

GATTI, B. A. Formação inicial de professores para a Educação Básica: pesquisas e políticas educacionais. In.: Est. Aval. Educ., São Paulo, v. 25, n.57, p. 24-54, jan./abr. 2014

HYPOLITO, A. M.; GARCIA, M. M. A.; VIEIRA, J. S. As identidades docentes como fabricação da docência. In.: Educação e Pesquisa, São Paulo, v. 31, n.1, p. 45-56, jan./abr. 2005.

HOFFMANN, J. Avaliação e Educação Infantil: um olhar sensível e reflexivo sobre a criança. ed. atual. e amp. Porto Alegre: Mediação, 2012. 
MONTEIRO, F. M. de A. (org.) Processo de aprendizagem profissional dos professores-formadores. In: Trabalho docente na educação básica: contribuições formativas e investigativas em diferentes contextos. Cuiabá: EdUFMT, 2007.

MONTEIRO, F. M. A.; FONTOURA, H. A. De ensinantes a aprendizes: investigação narrativa nos anos iniciais. In.: Pesquisa, formação $e$ docência: processos de aprendizagem e desenvolvimento profissional docente em diálogo. MONTEIRO, /Filomena Maria de Arruda (org.). Cuiabá: Editora Sustentável, 2017.

NÓVOA, A. (org.). Profissão professor. Lisboa: Ed. Porto, 1995.

PIMENTA, S. G. Formação de professores: identidade e saberes da docência. In: PIMENTA, S. G. (org.) Saberes pedagógicos e atividade docente. 8. ed. São Paulo: Cortez, 2012. p. 15-38.

TARDIF, M.; LESSARD, C. (org.) O ofício de professor: história, perspectivas e desafios internacionais. tradução de lucy magalhães. 2 ed. Petrópolis: vozes, 2008.

Recebido em: 14/02/2019

Aprovado em: 11/04/2019 